\title{
A EMPATIA NO RELACIONAMENTO TERAPÊUTICO: UM INSTRUMENTO DO CUIDADO
}

Telma Elisa Carraro ${ }^{1}$, Vera Radünz ${ }^{2}$

RESUMO: Acreditando que o relacionamento humano seja instrumento fundamental para o cuidado de Enfermagem e que o mesmo traga consigo uma força que tanto pode ser usada positive quanto negativamente, procuramos tecer algumas reflexões sobre o tema, perguntando: Como nos relacionamos com as pessoas? E estamos utilizando o relacionamento enquanto instrumento de cuidado? Apontamos a empatia como estratégia para atuação junto ao "ser cliente", para que o relacionamento se torne efetivamente terapêutico; aprimora-se assim o cuidado ao ser humano, sem desvalorizar outras estratégias.

DESCRITORES: Relações enfermeiro-paciente; Relações interpessoais; Empatia, Cuidado de Enfermagem.

\section{EMPATHY IN THE THERAPEUTIC RELATIONSHIP: A CARING SKILL}

ABSTRACT: We believe that establish relationship is a fundamental skill for Nursing care, wich can traduce a negative or a positive force. It depends in wich way it is used. Therefore, some considerations were made and we ask: How do myself relate to others? And how am I utilizing the relationship as caring skill? Empathy is pointed out as a strategy to improve care, without devaluating other communication elements.

DESCRIPTORS: Nurse-patient relations; Interpersonal relations; Empathy; Nursing care.

\footnotetext{
${ }^{1}$ Professora do Departamento de Enfermagem da Universidade Federal do Paraná. Mestra em Assistência de Enfermagem. Doutoranda em Filosofia da Enfermagem pela Universidade Federal de Santa Catarina.

${ }^{2}$ Professora do Departamento de Enfermagem da UFSC. Mestra em Assitência de Enfermagem. Doutoranda em Filosofia da Enfermagem pela UFSC.
} 


\section{ALGUMAS REFLEXÕES...}

Acreditando que o relacionamento humano seja instrumento fundamental para a Enfermagem, queremos compartilhar algumas reflexões a respeito. Tendo como pano de fundo nossa vivência enquanto enfermeiras, percebemos que o relacionamento traz consigo uma força que tanto pode ser usada positiva quanto negativamente. É que nem sempre estamos preparados para usa-la de forma positiva, ou seja, terapeuticamente.

Iniciamos então refletindo sobre o seguinte questionamento: Como nos relacionamos com as pessoas? Com pessoas que caminham, que comem, que trabalham, que estudam, que se divertem, enfim que levam uma vida "saudável"? No entanto não nos relacionamos apenas com pessoas "saudáveis". No nosso cotidiano profissional, convivemos e trabalhamos com pessoas que não podem caminhar, por estarem restritas a leitos... que não se alimentam normalmente. Que muitas vezes dependem de uma sonda de auxílio... que não podem correr por apresentar um problema cardíaco... que estã̃o com um corte no abdome, ou na cabeça, ou em qualquer outro lugar do organismo e que sentem dor ao se mexer... Convivemos com pessoas que precisam de nós até para respirar, algo tão vital! Mas que, em determinado momento, dependem de um cateter de oxigênio, ou de uma nebulização, ou mesmo de alguém que eleve a cabeceirta de sua cama ou que lhe desobstrua as vias aéreas superiores. São tantas as situções! Todas envolvendo seres humanos, que em determinando momento precisam, ou mesmo dependem de nós.

Como então nos relacionamos com essas pessoas, com as quais convivemos no nosso dia - a - dia profissional? Como são essas pessoas? Serão elas iguais uma às outras por estarem na condição de clientes? São todas seres humanos, sim, mas cada uma se apresenta em sua singularidade. Elas continuam pessoas singulares, "sendo" clientes ou "estando" clientes, e chegam até nós, não esvaziadas, mas acrescidas de um problema de saúde, dos mais diversos possíveis, trazendo consigo suas crenças, seus valores, seus conceitos, seus objetivos de vida... Temos nós observado essa singularidade dos seres humanos clientes?

E quanto ao controle que cada um necessita exercer sobre sua vida, temos nós respeitados essas pessoas enquanto clientes? Ou será que por estarem com uma incisão cirúrgica ou uma insuficiência renal ou cardíaca, ou uma fratura, ou mesmo uma "simples gripe", elas perdem sua capacidade de pensar, de decidir? Perdem seu querer? Seu fazer? Devemos sim considerar essa "bagagem de vida" que as pessoas trazem consigo, valorizando-as em nossos cuidados.

Portanto, precisamos instrumentalizarmo-nos para cuidar pois, como diz Radünz (1994), não é simplesmente ao vestir branco que nos tornamos profissionais eficientes e calmos, como num passe de mágica...

Assim, essas reflexões nos conduziram a uma busca de fundamentação teórica sobre a utilização da empatia como estratégia da qual podemos lançar mão para aprimorarmos nosso relacionamento terapêutico, desenvolvendo efetivamente, o cuidado ao ser humano.

\section{EMPATIA: UMA ESTRATÉGIA PARA RELACIONAMETO TERAPEUTICO}

Empatia, do grego emphatéia significa entrar no sentimento, termo inicialmente utilizado pelos teóricos da estética, para designar a capacidade de perceber a experiência subjetiva do outro (GOLEMAN, 1995).

Mas como é isto? E o estar com? É o sentir com? É o colocar-se no lugar do outro? E será isto possível? Vejamos o que alguns autores nos dizem a respeito.

Segundo Fish \& Shelly (1986, p. 110) "empatia é a capacidade de entender aquilo que uma pessoa está sentindo e transmitir-lhe compreensão, mantendo ao mesmo tempo certa objetividade para poder prestar a ajuda necessária". Ainda segundo essas autoras, dois outros elementos podem evidenciar-se numa relação interpessoal. Um deles, a simpatia, aquele primeiro contato, primeiro olhar, primeiro sorriso... $\mathrm{O}$ outro, a intelectualização, onde se observam e se coletam dados objetivamente, sem se envolver. Elas afirmam que somente quando sentimentos e fatos são colocados lado a lado e objetivamente analisados se chegará a descobrir a(s) causa(s) de o cliente se sentir como se sente; podemos entạ̃o, prestar a ajuda necessária, ou seja, agir com empatia (RADÜNZ, 1994).

Tschudin (1987) salienta que a empatia é a base para a relação de ajuda e que até pode ser definida, contudo não pode, na realidade, ser descrita, pode somente ser vivenciada e reconhecida. Para ela "Empatia é mais do que palavras, é ser, e ser com. [...] não é apenas algo que fazemos, é algo que somos" (p.34, 37). Reforça que a empatia é mais que um instrumento na relação terapêutica, "... é uma maneira de ser" (p.44). Conforme a autora dois outros elementos podem estar presentar na relação intrerpessoal: a simpatia e a antipatia.

Eva Botten (1991, p.155) conceitua empatia como sendo "a habilidade para entender o que a outra pessoa experiência e por que ela reage de uma maneira peculiar. E a habilidade para estar próximo à outra pessoa; estar presente e ser capaz de compartilhar os sentimentos da outra pessoa". Para a autora a empatia não é vista apenas como base para o relacionamento terapêutico, mas também como estratégia para evitar o "burnout", ou seja o desgaste físico e emocional, associado ao trabalho profissional.

Morse et al (1992), ao analisarem o conceito empatia indicam que o mesmo possui componenetes morais, emotivos, cognitivos e comportamentais. Salientam que existe confusão entre o significado da empatia e de seus componentes, a qual provém da natureza subjetiva do conceito, da complexidade do processo empático e da incompleta e acrílica conceptualização da empatia na literatura. Sugerem a continuidade de estudos sobre a temática, e que outras estratégias de relacionamento terapêutico sejam também valorizadas, estudadas e utilizadas pela Enfermagem, tais como simpatia, piedade consolo, compaixão e comiseração. Morse et al ainda nos alertam: “...quando os enfermeiros utilizam a empatia como 'conceito guarda chuva' correm o risco de interpretar erradamente as respostas à comnunicação. Isto confunde, ao invés de explicar claramente o que os enfermeiros fazem" (1992, p. 278).

Goleman (1995), cita a teoria do psicólogo americano Titchener, onde esse defendia que a empatia provinha de uma espécie de imitação física da angústia de outra pessoa, que então evoca em nós os mesmos sentimentos. Buscou uma palavra diferente de simpatia, pois para ele simpatia se pode sentir pela atitude geral do outro, sem compartilhar o que a outra pessoa está sentindo.

Atualmente com o despontar da tese científica da Inteligência Emocional, o psicólogo norte americano Daniel Goleman (1995) afirma que o controle das emoções é fator essencial para o desenvolvimento intelectual do indivíduo. Nessa tese ele aborda a importância da empatia, salientando que "todo relacionamento, raiz do envolvimento, vem da sintonia emcional, da capacidade de empatia" (p.109).

Apesar dos diferentes enfoques e abordagens sobre a utilização da empatia como estratégia para o relacionamento terapêutico e portanto para um efetivo cuidado ao ser humano, percebemos que os estudiosos do assunto são unânimes em afirmar a importância da empatia para tal. Os estudos a respeito da empatia, por nós revisados, apontam para a necessidade do aprofundamento do tema, pois este está longe de ser esgotado. Por outro lado, existe uma preocupação em não desmerecer outros elementos para um relacionamento rterapêutico, tais como simpatia, comiseração, compaixão, já citados anteriormente, os quais podem ser utilizados conjuntamente com a empatia. Muitas vezes é disto que o outro precisa: sentir que estamos com ele, junto dele! E este "estar com" pode tomar diversas formas: o segurar suas mãos, o sorrir, o secar seu suor, um olhar... O ouvir, sim! Nem sempre precisamos falar! Muitas vezes é preciso ouvir e demonstrar: estou aqui!

\section{ILUSTRANDO*}


Tschudin (1987) nos conta uma história que, em nosso entendimento, ilustra muito bem as diferenças entre os possíveis elementos que podem estar presentes num relacionamento interpéssoal, salientando a importância da empatia para que este seja terapêutico.

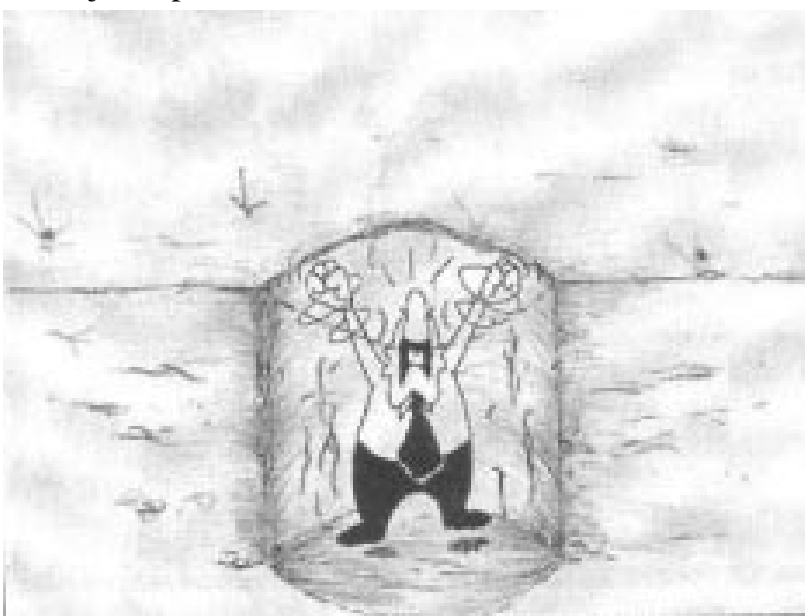

Se uma pessoa caiu num buraco...

Se você agir com simpatia:

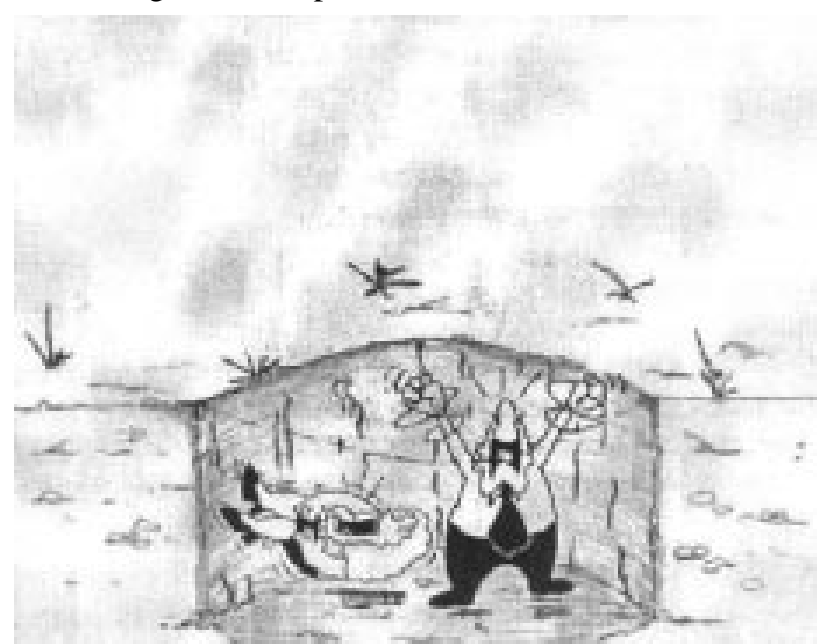

Entra e chora com ela;

Se você agir com antipatia:

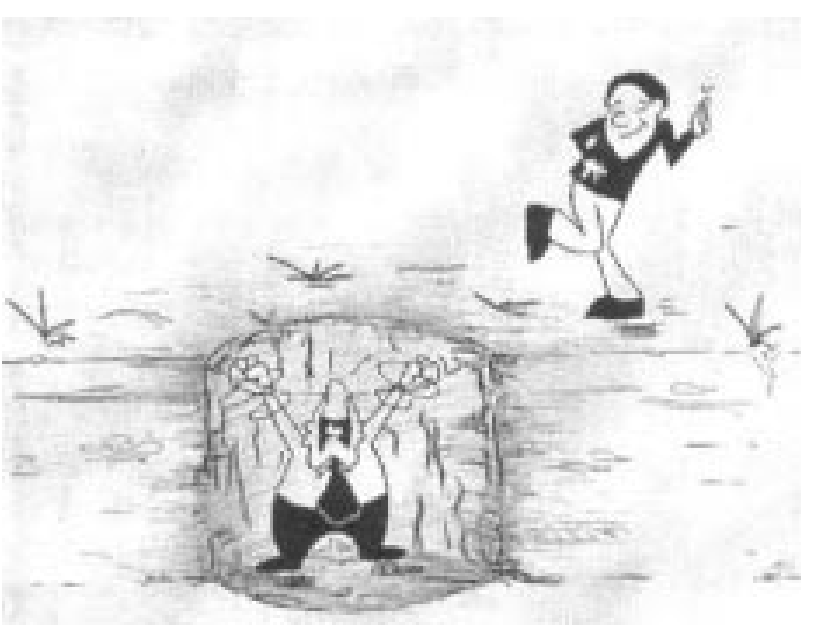

Passa ao lado e nem olha;
Se você agir com empatia:

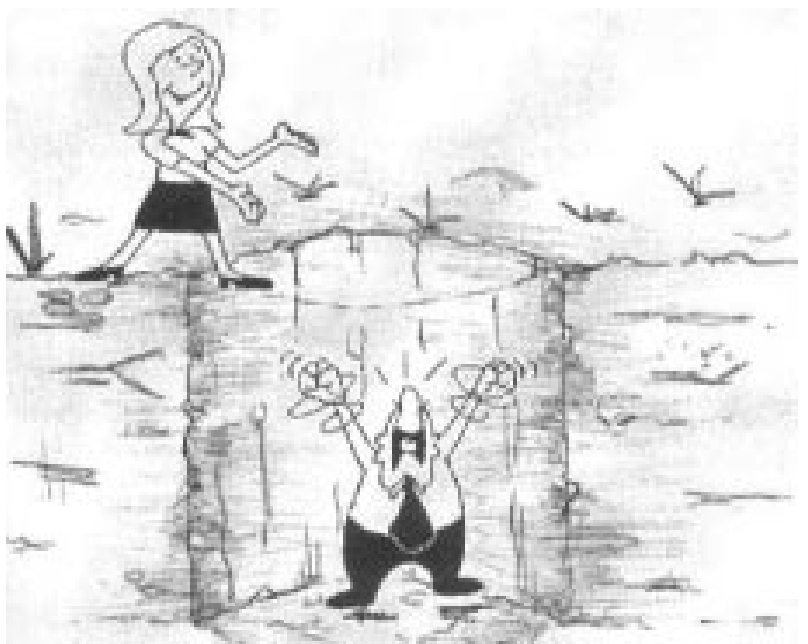

Você empresta forças à pessoa, ou seja coloca um pé no buraco e ajuda o outro a sair do buraco.

Com base nesta história dos "buracos" de Tschudin, convidamos para uma reflexão perguntando:

\section{Você tem...}

Passado pelo buraco?

Entrado no buraco?

Ou ajudado o outro a sair do buraco?

\section{REFERÊNCIAS}

1. BOTTEN, Eva. How to survive in cancer care. In: INTERNATIONAL CONFERENCE ON CANCER NURSING, 6, 1990. Amsterdam. Anais. Great Britain: GRESHAM, 1991.

2. FISH, Sharon; SHELLY, Judith Allen. Cuidado spiritual do paciente. São Paulo: Umhe, 1986.

3. GOLEMAN, Daniel. Inteligência emocional. Rio de Janeiro: Objetiva, 1995.

4. MORSE, Janice M. et al. Exploring empathy: a conceptual fit for nursing practice? Journal of Nursing Scholarship, v. 24, n.4, p. $273-280,1992$.

5. RADÜNZ, Vera. Cuidando e se cuidando: fortalecendo o "self" da enfermeira. Florianópolis, 1994. Dissertação (Mestrado em Enfermagem) - Centro de Ciências da Saúde, Universidade Federal de Santa Catarina.

6. TSCHUDIN, Verena. Counselling skills for nurses. 2 ed. London: Bailliére, 1988.

* A idéia da ilustração gráfica dos "buracos" surgiu em nossa imaginação tão logo lemos a história de Tschudin. Para concretiza-la, além do recurso da computação gráfica pudemos contar com o dom artístico de Emerson Chaoui Santos. 